\title{
Fifty years of Fuzzy Research: a bibliometric analysis and a long-term comparative overview
}

\author{
Jaime A. López-Guauque ${ }^{\mathrm{a}^{*}, \text { Anna M. Gil-Lafuente }}{ }^{\mathrm{a}}$ \\ ${ }^{a}$ Department of Business Organization, Universitat de Barcelona, Av. Diagonal 690, 08034 Barcelona, Spain
}

\begin{abstract}
This paper presents a general overview and a long-term comparison in fuzzy logic research published between 1965 and 2017, obtained via Web of Science. The paper analyzes the growth, impact, trends and regional localization of fuzzy research. Conventional, sophisticated among others bibliometric indicators have applies. It aggregates the information according to different levels and criteria including researchers, publications, institutions, or countries. A global perspective have been provided through comparisons of regional aggregates and compound annual growth rates that strengthen the indicators applied in this article. The results permit to visualize the influence, importance, evolution and performance of the fuzzy research as well its contribution to, and transversality with other fields. The findings show that China continues to be a leader in number of contributions. There has been a recent relative decline in the United States contributions overall. Asian and African contributions to scientific literature have grown noticeably. The results also provide a framework for the use of indicators adjusted to specific contexts and relevant information for future research.
\end{abstract}

Keywords: Fuzzy logic, Bibliometrics, Scientometrics, Web of Science, Research indicators, H-index, CAGR.

\section{Introduction}

The need to measure the results of scientific production, its impact and dissemination, is regaining strength in the constant search to find indicators or proxies to evaluate the transfer and efficiency of science and technology in a world of great and rapid change. The importance of measuring research activity and science itself is sustained by the very processes of science by generating scientific information on its performance. In addition, an involvement by state bodies and institutions that allocate resources to sustain the scientific activity and productivity of scientists contribute to the development of the same.

Bibliometric can be considered a proxy between scientific production and knowledge in terms of quantity. Its first definition goes back to the concept of statistical literature, applied for the first time by Hulme [23], other concepts were introduced by Otlet [34], Raising [38], Pritchard [37], Hawkins [18],
White and McCain [45]; all conclude that corresponds to a quantitative analysis whose base is the bibliography. Carrizo [7], introduces a more recent concept, bibliometrics is "the set of methodological knowledge for the application of quantitative techniques for the study of the processes of production, communication and the use of scientific information, in order to contribute to analysis and evaluation of science and research." There are other concepts that tend to be confused with bibliometric, such as scientometrics, informetrics and almetrics.

Making a brief journey through the evolution of bibliometric indicators, we find Cole and Eales in 1917, as pioneers. Among others pioneers, including can cited Alfred Lotka, [28] who created the first biblio-metric law, called "Law of Lotka"; Samuel Bradford [4], with the "Bradford's law"; George Kingsley Zipf, presented "Zipf's Law." In the mid-1950s, Eugene Garfield, created the Science Citation Index (SCI) and the Journal Impact Factor - JIF [13; 14]; in

\footnotetext{
*Corresponding author. Jaime A. López Guauque, Faculty of Economic and Business, Universitat de Barcelona, Av. Diagonal 690, 08034 Barcelona, Spain. E-mail: jalopez@ub.edu
} 
the seventies, studies by Francis Narin. In the nineties, in Europe, many of the specialized Research and Development-R\&D structure indicators became Science and Technology observatories. Recent indicators have been emerged, such as the h-index [19], field normalized citation [43], SJR [16], CiteScore (Elsevier, 2016).

In the five decades of constant advances in the field of research into fuzzy logic, it is worth noting the pioneer and seminal work of Lofti A. Zadeh, who is considered to be the father of the field, and who formulated a solution to the dichotomy between human reasoning and bivalent or classical logic, introduced his pioneer work Fuzzy sets in 1965 which was published in Information \& Control. [50] It is the most cited document in the area of computer science, according to the Web of Science (WoS) [39]. This work not only permits the theorization of the concepts of fuzzy subsets, but it also brought, at that time, a light on the turmoil and need to deliver scientific and mathematical models that reproduced the theoretical approaches through simulations.

In the early years, this research generated scepticism and little attention on the part of the conservative scientific community of the time. Over time, however, the number of followers grew. Years later, towards 1973, the increase in the number of enthusiastic scientists and followers of the works of Zadeh was important. This, in turn, stimulated and inspired the development and application of the field, especially amongst the most innovative scientists. By then, Zadeh had introduced new concepts and derived ideas. These are highlighted in his article "Fuzzy Algorithm" (1968) along with the formal methodological elements which are highlighted in his article "Quantitative Fuzzy Semantics" (1971). The development and incorporation of these theories was presented mainly in Japan (technological advances, research groups at Tokyo University, Kyoto University, Osaka University), South Korea, China and India. In the United States and Europe, the incorporation took place more slowly. The application of fuzzy logic to control brought about the first fuzzy boom, attracting, before its time, a large audience of academic researchers and corporate engineers who found supervisors for their thesis in industrial applications.

The scientific community began to organize themselves with the emergence of various professional, national and international associations which had a specific focus on research into fuzzy logic. The creation of the first full-time international Journal of Fuzzy Sets and Systems, in 1978, constitutes the con- solidation of the field. Associated with this are organizations and professional associations, such as the one created in 1982, the North American Fuzzy Information Processing Society (NAFIPS). The International Fuzzy Systems Association (IFSA) held its first conference in Spain in July 1985; its beginnings go back in the high increase and interest by the fuzzy research of large number of researchers, especially from Europe and Asia, in the 70s. In the 1990s, an important consolidation process took place with the creation of the Institute of Electrical and Electronics Engineers Computational Intelligence Society (IEEE CIS), since then, diffuse research would have been officially recognized, integrating itself into the three main branches and institutionalizing itself in the scientific community. The organization of fuzzy science is divided into two parts; one part which belongs to the IEEE CIS, and the other part which belongs to the IFSA association.

Zadeh coined the title Soft Computing to include neural network and genetics algorithm techniques, a broader category for the interests of artificial intelligence and computer science researchers.

At present, fuzzy research is an established scientific field with a thousand members. The field has been developing research with successful application approaches in neural networks, data mining, clusterisation, artificial intelligence, control theory, inference and reasoning, chaos theory, among others. The various theories about fuzzy logic are expanded in Zadeh [50,51,52], Bustince et al. [5], Dubois and Prade [10], Klir and Yuan [25], Zimmer-mann [54].

Through bibliometric analysis, it can get an overview of a field of research, methodologies and different approach that each researcher pursues. Many authors have performed bibliometric studies in certain fields of research, for example, operations, production [21,22,35], management [36], computational intelligence [42], ecological economics [20], innovation [12], econometrics [2], business and economics [31], among others. In the field of fuzzy research, many studies have provided bibliometric overview. Among others, Merigó [30]who presented a general overview of fuzzy research using bibliometric indicators. In addition, Merigo et al.[32] presented the leading tendencies in the field with the analysis of an important and influential journal using bibliometric indicators. Cobo et al. [8] presented an informetric method to visualize the evolution of the Fuzzy Sets field. Similarly, other authors have applied metrics using a citation network analysis, for example; in the development of the OWA field[11]; in the development track of IFS; in the development of aggregation 
operator [48]; and the most recent work [49,26] on linguistic decision making through cite space visualization method; not to mention, Blanco-Mesa et al. [3] who also used a bibliometric approach to review a fuzzy decision-making field. Some other authors provide a bibliometric analysis for the journals anniversary $[6,15,32,33,44]$.

No paper has been published providing a general overview of fuzzy research with comparative aggregations and sophisticated indicators in the long run. The paper is organized as follows. Section two describes the methodology used. Section three presents the overall results covering the period 1965-2017, including subdivisions by author, journal, country, institutions and research area, analyzing the top most cited papers. Section four shows a regional comparative analysis of the last ten years. Section five discusses the main findings.

\section{Methodology}

This study will provide a historical overview on the evolution of fuzzy research through bibliometric analysis since Zadeh published his seminal paper on "Fuzzy sets," 52 years ago. In the first instance, an analysis of the activity of scientific production for all parties involved, at all levels and areas, not only for researchers, but also for publishers, journals, institutions and countries. On the other hand, the study will indicate the historical development of the field, analysing the production, trends of authors and journals, and uses of the results. These results give an informative overview of the current state of the field of fuzzy logic in the WoS.

The approach taken is that of the point of view of information sources from databases to consulting the WoS owned by Thomson Reuters. It was decided to use this database which is considered the world's leading source of intelligent information. It is a pioneering database which has been used for citation indexing for the past six decades now. Other existing databases that may be considered are Scopus, Emerald, Google Scholar and Redalyc. The WoS is a high impact database that brings together over 6 secondary databases in various fields of science, indexes over 33,000 journals including more than 100 million records. In the field of social sciences, it covers 5,300 publications in 55 disciplines with more than 8.5 million records.

The data are obtained from WoS database. Our focus is in the WoS Core Collection, which considers several sub databases, including the Conference Proceedings Citation Index.

The period of analysis covers 1965-2017. A comprehensive global analysis of the past fifty-two years is carried out. In regional analysis, data from the last ten years have been selected. For the specific analysis, the parameters for the number of citations for the first top publications have been selected. Importantly, the dynamics of updating the WoS database is between the months of June / July each year (Journal Citation Report - JCR: last updated on 6/14/2017). Therefore, the 2017 data presented has been updated. In the search process, in July 2017, the keywords "fuzzy and soft computing" were selected in the section topic keywords, obtaining 192,608 entries, which reflects the total WoS publications. For the period of the five decades (1965-2017), updating data was performed of July 2017 (the total of records in the WoS database consultation to date exceeded 64.8 million records).

In this analysis, 173,695 records were given for Fuzzy. This number includes all the publications covered by the WoS database. The WoS comprises twenty different types of publications, including articles, proceedings, review, letters, notes, book reviews, meeting abstract and editorial material. Note that in recent years, fuzzy research has become a broader field known as soft computing. Therefore, these data have been ignored in the analysis since the ratio of the subfields may bring about this limitation. Also many of the documents that use the word fuzzy are not related to fuzzy research. Consequently, these works were excluded from the analysis given that the approximation is compensated between them.

This information has been filtered to look just for articles and reviews, focusing on the main articles. Therefore, the total number of publications found has been reduced to 88,394 documents (articles+review), all the papers related to fuzzy research. Some statistics and citation analysis methodologies have been used to visualize the current status in fuzzy research. A conventional indicators, based on publications and citation counts, such as number of publications and the number of citations, was used. Sophisticated indicator like as Impact Factor (IF), h-index, Highly Cited Papers (HC) have also been shown. Another one selected the publications in the top list on each analysis unit. The minimum number of documents suitable for quantitative research is a much discussed topic. Experience has shown that between 20 and 50 documents are generally considered appropriate. 


\section{Results}

The fuzzy research presents a growth and influence with a notable increase in the last ten years, as shown in Figure 1; more than 8000 papers are published each year in this field, with a remarkable number of 14,000 records for 2016, representing the highest record of annual publications in the fifty-two years analyzed. A slight decrease of total publications for 2010, although the opposite is true with respect to articles that are at the same level this year without any noticeable changes. The number of documents for 2011 and 2012 are very similar to those presented for the years 2007 and 2008 respectively.

The growth in the number of publications can be explained by the increase in the number of fuzzy journals that have come into existence and by those that have been indexed in the WoS database. The number of journals with fuzzy topics in 2005 was 389 as opposed to 866 in 2016. That is, a variation of 355 journals, representing a 123 percent increase and an annual growth rate of 7.55 percent. This indicates a notable and growing influence of fuzzy research, and the expansion of the WoS, with more journals related to this field being indexed. The increase is also due to a gradual increase in the number of researchers in the field. The proportion of articles of all works published each year has increased from 50 percent in 2005 to 59 percent in 2016. At least, sixtyfive percent of the total fuzzy production has been performed in the last ten years. The sum of documents in the first 40 years is surpassed in the next seven years (2005-2011) $(30 \%)$ and it doubles when contemplating publications in the last ten years $(60 \%)$.

Zadeh's work [50] stands out, with more than 26,200 citations, constituting the most cited document in the area of computer science, according to WoS. Citation data should be treated with caution, speed of publication in each field varies greatly as the rate of citation. High citation rates are correlated with other qualitative assessments of performance such as peer review (WoS). The citation rate is normal, considering the patterns of computer science and engineering. It is noteworthy that the material indexed in the WoS is estimated to contain about 95 percent of the world citations. The average citation rate for computer science and engineering are low.

\subsection{Citation structure of Fuzzy research}

Table 1, presents the general citation typology of the all papers, a classification structure of all documents is observed, taking into account the number of citations, the relative values in each range, maximum and minimum values of each range and the position of the maximum value of each range. Also, Figure 2 presents the maximum and minimum values for each of the mentioned categories of citations shown.

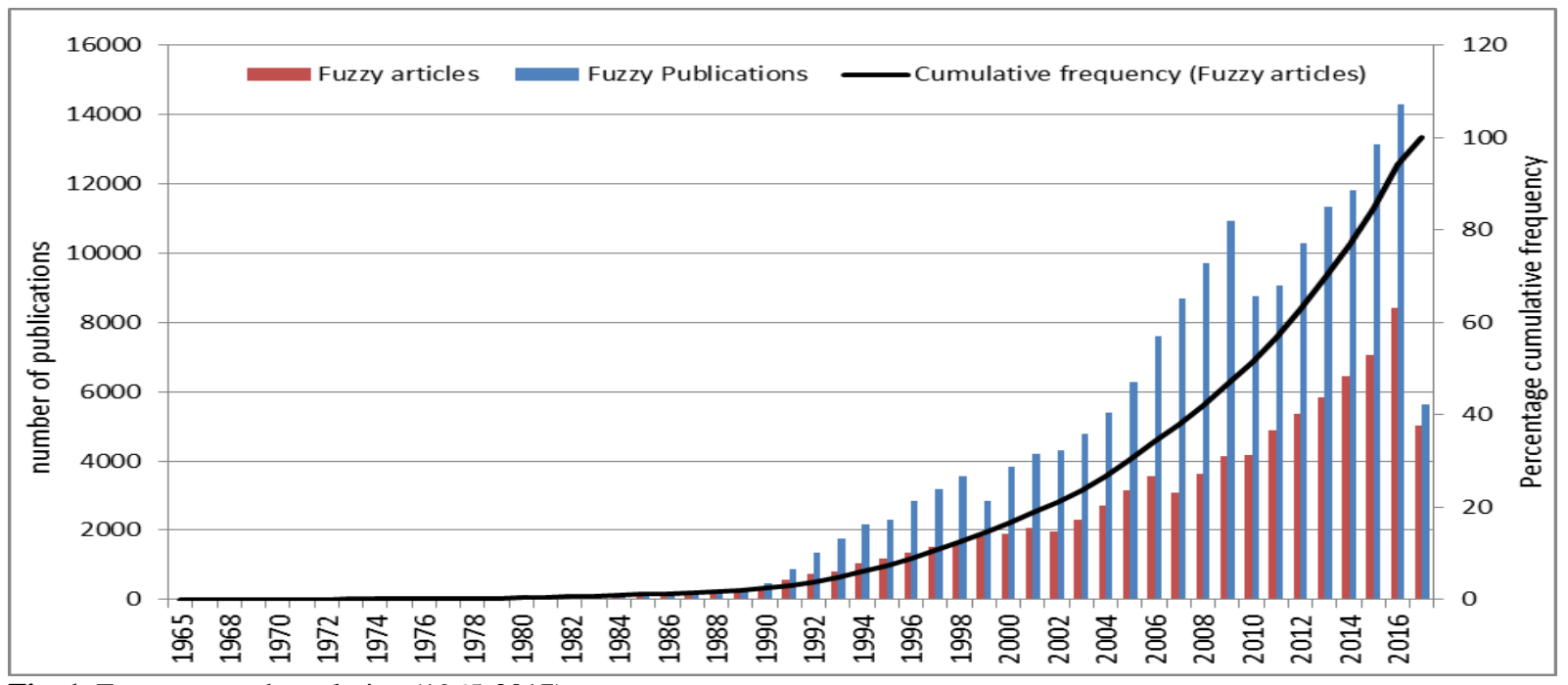

Fig. 1. Fuzzy research evolution (1965-2017)

Note: The chart shows the number of annual publications in fuzzy research from 1965 to 2017. (2017: includes seven months). The blue bars indicate the total number of fuzzy documents published each year in the WoS whereas the red bars correspond to the total number of fuzzy articles published each year in the WoS. The black line indicates the cumulative frequency of fuzzy articles.

Source: Own elaboration from WoS. 
Table 1. General citation typology in fuzzy research in WoS

\begin{tabular}{lrrrrr}
\hline \multicolumn{1}{c}{$\begin{array}{c}\text { Number of } \\
\text { citations }\end{array}$} & $\begin{array}{c}\text { Num- } \\
\text { ber of } \\
\text { papers }\end{array}$ & $\begin{array}{c}\text { \% pa- } \\
\text { pers }\end{array}$ & $\begin{array}{c}\text { Max } \\
\text { citation }\end{array}$ & $\begin{array}{c}\text { Min ci- } \\
\text { tation }\end{array}$ & $\begin{array}{c}\text { Rank- } \\
\text { ing }\end{array}$ \\
\hline More than 2000 & 7 & 0.01 & 26228 & 2522 & 1 \\
$1000-1999$ & 20 & 0.02 & 1612 & 1042 & 8 \\
$500-999$ & 88 & 0.10 & 987 & 500 & 28 \\
$250-499$ & 283 & 0.32 & 499 & 250 & 116 \\
$100-249$ & 1725 & 1.95 & 249 & 100 & 399 \\
$50-99$ & 4041 & 4.57 & 99 & 50 & 2124 \\
$1-49$ & 64908 & 73.43 & 49 & 1 & 6165 \\
No citations & 17322 & 19.60 & 0 & & 71073 \\
\hline
\end{tabular}

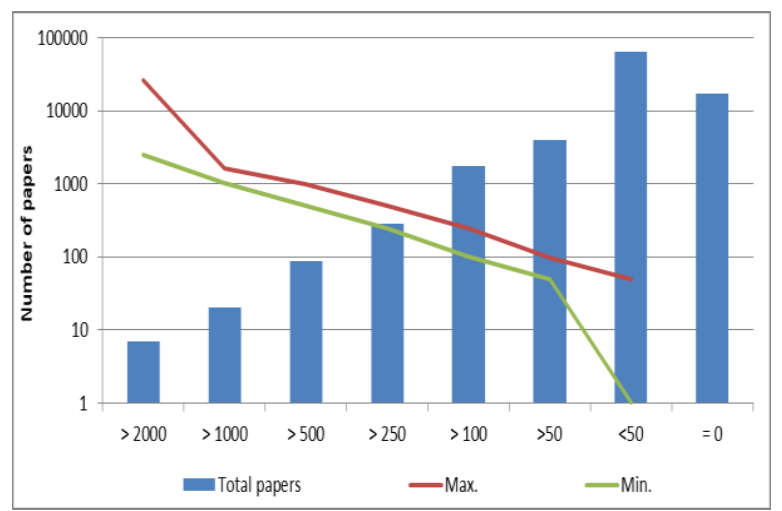

Fig. 2. General citation structure in fuzzy research in WoS. Maximum and minimum values. Note: The abscissa indicates number of citations

Only seven works have received more than 2000 citations and two percent of publications have more than 100 citations. The largest number of publications is in the range of dates between one and fortynine. There are a high number of publications that do not record citations which corresponds to 20 per cent of all documents. The efficiency principle of Pareto1 could be understood - if the citation was considered a benefit, it would be thought that, at least, 80 per cent would enjoy having it and 20 per cent would not.

Analyzing the field of fuzzy logic, the global $h$ index 2 is 295 . Specifically, 295 documents have received at least 295 citations for the period.

\subsection{Most influential journals in fuzzy research}

The number of journals that come under the title of fuzzy logic is broad. Many current journals are de-

\footnotetext{
${ }^{1}$ Vilfredo Pareto (1971) Pareto Principle, also called $\mathrm{Pa}-$ reto optimality, or Pareto efficiency.

${ }^{2}$ See Hirsch [19]; Alonso et al. [1]; Martinez et al. [29]; Żogała-Siudem et al. [55]
}

voted exclusively to the field. Another category is that which publishes documents. Journals with publications in FL include those that are influential. Others that are newer have a clear focus on the field. In Table 2, the most influential journals in fuzzy field are listed according to the number of publications; only journals with at least 500 publications are shown.

The three most influential journals on FL are Fuzzy Sets and Systems, IEEE Transactions on Fuzzy Systems and Information Sciences, according to the H-index. IEEE Transactions on Fuzzy Systems is the most influential journal of all time in fuzzy research, according to the impact factor-IF, highly cited papers, hot papers and Top 100, where it registered the highest values. Some other influential journals are Expert Systems with Applications, Journal of Intelligent Fuzzy Systems, Applied Soft Computing, Soft Computing, Neurocomputing. Other recent journals that are popular with the scientific community are Soft Computing and Applied Soft Computing. Other journals dedicated exclusively to the field are: Journal Intelligent \& Fuzzy Systems, Fuzzy Optimization and Decision Making, Int. J. Fuzzy Systems and the Iranian J. Fuzzy Systems. Other journals that publish occasional articles in the field are: IEEE Transactions on Systems, Man and Cybernetics, European J. Operational Research, the IEEE Transactions on Neural Networks, Journal Mathematical Analysis and Applications, IEEE Transactions on Industrial Electronics and Pattern Recognition.

A few other journals that are not indexed in the WoS are: Advances in Fuzzy Mathematics, Advances in Fuzzy Sets \& Systems, Advances in Fuzzy Systems, Annals of Fuzzy Mathematics and Informatics, BUSEFAL, Asian J. Fuzzy and Applied Mathematics, Annals of Fuzzy Sets, Fuzzy Logic and Fuzzy Systems, CiiT Int. J. Fuzzy Systems, Fuzzy Economic Review, Fuzzy Information and Engineering.

\subsection{Impact indicator in Fuzzy research}

Table 3 presents the impact indicator in Fuzzy research per year, as a measure of quality. At WoS corresponds to the Journal Citation Report (JCR or IF). The JCR (or IF) is calculated by dividing the number of citations received in the year $n-1$ and $n-2$ from the year " $n$ " by the total number of articles published in year n-1 and n-2. Also, the h-index per year is included. The results are shown in Table 3. 
Table 2. Most influential journals in fuzzy research

\begin{tabular}{|c|c|c|c|c|c|c|c|c|}
\hline Journal & TPF & $\% \mathbf{P F}$ & $H$ index & TCF & IF & $\mathrm{HC}$ & HP & T100 \\
\hline Fuzzy Sets and Systems & 6468 & 7.32 & 155 & 173252 & 2.718 & 20 & 0 & 10 \\
\hline Information Sciences & 2220 & 2.51 & 102 & 61880 & 4.832 & 81 & 1 & 6 \\
\hline Expert Systems with Applications & 2208 & 2.50 & 83 & 50156 & 3.928 & 59 & 0 & 0 \\
\hline Journal of Intelligent Fuzzy Systems & 2029 & 2.30 & 29 & 6632 & 1.261 & 9 & 0 & 0 \\
\hline IEEE Transactions on Fuzzy Systems & 1910 & 2.16 & 142 & 95137 & 7.671 & 101 & 7 & 17 \\
\hline Applied Soft Computing & 1411 & 1.60 & 55 & 18980 & 3.541 & 30 & 0 & 0 \\
\hline Soft Computing & 920 & 1.04 & 34 & 7774 & 2.472 & 4 & 1 & 0 \\
\hline Neurocomputing & 777 & 0.88 & 37 & 8223 & 3.317 & 6 & 0 & 0 \\
\hline $\begin{array}{l}\text { International Journal of Uncertainty Fuzziness and Knowledge } \\
\text { Based Systems }\end{array}$ & 727 & 0.82 & 40 & 7479 & 1.214 & 1 & 0 & 0 \\
\hline International Journal of Intelligent Systems & 673 & 0.76 & 49 & 11411 & 2.929 & 8 & 0 & 2 \\
\hline Mathematical Problems in Engineering & 662 & 0.75 & 13 & 1295 & 0.802 & 4 & 0 & 0 \\
\hline International Journal of Advanced Manufacturing Technology & 623 & 0.70 & 34 & 6636 & 2.209 & 0 & 0 & 0 \\
\hline European Journal of Operational Research & 605 & 0.68 & 82 & 27059 & 3.297 & 16 & 0 & 3 \\
\hline $\begin{array}{l}\text { International Journal of Approximate Reasoning } \\
\text { IEEE Transactions on Systems Man and Cybernetics Part B }\end{array}$ & 569 & 0.64 & 58 & 13835 & 2.845 & 4 & 1 & 0 \\
\hline Cybernetics & 565 & 0.64 & 83 & 26940 & 6.220 & 12 & 0 & 6 \\
\hline Engineering Applications of Artificial Intelligence & 550 & 0.62 & 39 & 7668 & 2.894 & 1 & 0 & 0 \\
\hline International Journal of Fuzzy Systems & 528 & 0.60 & 21 & 2684 & 2.198 & 3 & 0 & 0 \\
\hline
\end{tabular}

Abbreviations: TPF and TCF, total papers and citation only with fuzzy; \%PF, percentage of participation; $\mathrm{H}$-index only with fuzzy; IF, impact factor; $\mathrm{HC}^{\mathrm{a}}$, number of Highly Cited in Fuzzy; HP ${ }^{\mathrm{b}}$, number of Hot papers in fuzzy; T100, number of the papers in the top 100 most cited papers in fuzzy research of all time.

${ }^{a}$ Highly Cited Papers: Selected from the most recent 10 years of data, HCP reflect the top $1 \%$ of papers by field and publication year based on a highly cited threshold. It helps identify and refine the most influential research papers.

${ }^{b}$ Hot papers: are selected by virtue of being cited among the top one-tenth of one percent $(0.1 \%)$ in a corrent bimonthly period. Papers are selected in each of 22 fields of science and must be published within the last two years.

Source: Own elaboration from Web of Science

Table 3. Impact indicators in fuzzy research

\begin{tabular}{lrrrrrrrrrrrr}
\hline & $\mathbf{2 0 0 5}$ & $\mathbf{2 0 0 6}$ & $\mathbf{2 0 0 7}$ & $\mathbf{2 0 0 8}$ & $\mathbf{2 0 0 9}$ & $\mathbf{2 0 1 0}$ & $\mathbf{2 0 1 1}$ & $\mathbf{2 0 1 2}$ & $\mathbf{2 0 1 3}$ & $\mathbf{2 0 1 4}$ & $\mathbf{2 0 1 5}$ & $\mathbf{2 0 1 6}$ \\
\hline T.papers & 3139 & 3563 & 3085 & 3615 & 4135 & 4154 & 4897 & 5347 & 5820 & 6436 & 7060 & 8434 \\
T.citations & 64607 & 74019 & 80335 & 79069 & 85960 & 74641 & 77213 & 66562 & 61698 & 47405 & 32999 & 13917 \\
T.citations n-1 \& n-2 & 5465 & 7557 & 9135 & 11628 & 15167 & 15206 & 17644 & 19656 & 23985 & 27643 & 30787 & 36990 \\
T.papers n-1 \& n-2 & 5026 & 5849 & 6702 & 6648 & 6700 & 7750 & 8289 & 9051 & 10244 & 11167 & 12256 & 13496 \\
Impact factor of year n & 1.09 & 1.29 & 1.36 & 1.75 & 2.26 & 1.96 & 2.13 & 2.17 & 2.34 & 2.48 & 2.51 & 2.74 \\
Average citations per item & 20.58 & 20.77 & 26.04 & 21.87 & 20.79 & 17.97 & 15.77 & 12.45 & 10.60 & 7.37 & 4.67 & 1.65 \\
$h$-index & 103 & 106 & 109 & 104 & 100 & 95 & 89 & 77 & 76 & 57 & 45 & 30 \\
\hline
\end{tabular}

The impact factor for 2005 was slightly above one. From 2009, the impact factor had increased to almost two, reaching 2.74 in the last year (2016). With respect to the citation impact (avg. citation per item) for 2007 was about 26, which in 2016 corresponded to 1.65 . Obviously, articles published in 2007 will generally have more citations than papers published in 2016. The citation count has gone down in recent years for any given period of time, since it has had less time to accumulate citations.

The number of citations received by scientific publications is considered a conventional indicator but in turn important and complementary in the evaluation of scientific performance. Although, many factors can influence the citation, its popularity and influence still to be force, despite the criticism received in the last years and limitations it presents.

\subsection{Most influential articles in fuzzy research}

Table 4 shows the top 20 Fuzzy articles by citations for the period analysed. Undoubtedly, the most cited and influential paper corresponds to Zadeh (1965), followed by the paper of Takagi and Sugeno, with more than 8,725 citations.

The most influential author is Zadeh, with more than 26,228 citations, which exceeds the total citations of the three authors who follow him. The number of documents published is not large, because in the beginning when the field was beginning to estab- 
lish itself, many documents were not written. Zadeh worked on documents alone, without co-authorship.
In the second position, we have Sugeno with 8725 citations.

Table 4. Top 20 fuzzy articles by citations for the period 1965-2017

\begin{tabular}{|c|c|c|c|c|c|}
\hline $\begin{array}{l}\text { Total Cita- } \\
\text { tions }\end{array}$ & Title & Author/s & Year & Age & C/year \\
\hline 26228 & Fuzzy sets & Zadeh, LA & 1965 & 52 & 504 \\
\hline 8725 & $\begin{array}{l}\text { Fuzzy identification of systems and its applications to modeling and } \\
\text { control }\end{array}$ & Takagi, T; Sugeno, M & 1985 & 32 & 273 \\
\hline 7486 & Fuzzy nanoassemblies: Toward layered polymeric multicomposites & Decher, G & 1997 & 20 & 374 \\
\hline 6239 & On ordered weighted averaging aggregation operators & Yager, RR & 1988 & 29 & 215 \\
\hline 5752 & Concept of linguistic variable and its application to AR I & Zadeh, LA & 1975 & 42 & 137 \\
\hline 5511 & Anfis - adaptive-network-based fuzzy inference system & Jang, JSR & 1993 & 24 & 230 \\
\hline 2809 & Intuitionistic fuzzy-sets & Atanassov, KT & 1986 & 31 & 91 \\
\hline 2566 & Experiment in linguistic synthesis with a fuzzy logic controller & Mamdani, EH; Assilian, S & 1975 & 42 & 61 \\
\hline 2522 & Fuzzy-logic in control-systems - fuzzy-logic controller .1 & Lee, $\mathrm{CC}$ & 1990 & 27 & 93 \\
\hline 1607 & $\begin{array}{l}\text { Survey over image thresholding techniques and quantitative perfor- } \\
\text { mance evaluation }\end{array}$ & Sezgin, M; Sankur, B & 2004 & 13 & 124 \\
\hline 1564 & A review on image segmentation techniques & Pal, NR; Pal, SK & 1993 & 24 & 65 \\
\hline 1548 & Application of fuzzy algorithms for control of simple dynamic plant & Mamdani, EH & 1974 & 43 & 36 \\
\hline 1508 & $\begin{array}{l}\text { An approach to fuzzy control of nonlinear systems: Stability and de- } \\
\text { sign issues }\end{array}$ & $\begin{array}{l}\text { Wang, HO; Tanaka, } \mathrm{K} ; \\
\text { Griffin, } \mathrm{MF}\end{array}$ & 1996 & 21 & 72 \\
\hline 1479 & Status of land cover classification accuracy assessment & Foody, GM & 2002 & 15 & 99 \\
\hline 1432 & Generating fuzzy rules by learning from examples & Wang, LX; Mendel, JM & 1992 & 25 & 57 \\
\hline 1382 & FCM - The fuzzy c-means clustering-algorithm & $\begin{array}{l}\text { Bezdek, JC; Ehrlich, R; } \\
\text { Full, W }\end{array}$ & 1984 & 33 & 42 \\
\hline 1347 & Stability analysis and design of fuzzy control-systems & Tanaka, K; Sugeno, M & 1992 & 25 & 54 \\
\hline 1302 & Structure identification of fuzzy model & Sugeno, M; Kang, GT & 1988 & 29 & 45 \\
\hline 1262 & Fuzzy logic equals Computing with words & Zadeh, LA & 1996 & 21 & 60 \\
\hline 1178 & Similarity relations and fuzzy orderings & Zadeh, LA & 1971 & 46 & 26 \\
\hline
\end{tabular}

Analyzing the typology by age of the documents in the top 100, we see that the publications of the last six years do not reach the level of citations to be included in the Top100 Rank in the fuzzy field. Fortythree percent of publications are in the range of 11 to 20 years, followed by the range between 21 and 30 years with 23\%. This period between 1986 and 2005, can be considered as a prosperous and growing period in the field, coinciding with what many authors call the third industrial revolution or digital revolution, initiated in the decade of the 80 s and that contributed with the applied development of the field.

Ten countries (China, USA, Taiwan, Iran, India, Spain, Canada, Turkey, England and South Korea) concentrate at least $80 \%$ of the total of fuzzy publications. At the top in the field of fuzzy research is the China with the largest number of citations. However, at the top 100, USA has the lead in number of citations.

\subsection{Most influential authors in fuzzy research}

An important aspect of the research is the consideration given to the most influential and productive authors. Table 5 presents a list with the Top 20 authors with the greatest number of papers in the fuzzy research of all time, by overcoming the 150 papers threshold. Note that many other indicators are shown in this table, allowing an integral comparison of each researcher. Zadeh is the most influential author in fuzzy research with the highest number of citations, but not for the number of papers compared with other authors. By highest number of fuzzy papers, we can noteworthy is Pedrycz with 544 articles, Huang is second with 316 and in third position with 275 is Yager. The HC and HP column can be considered as indicative of the influence of these key authors in this field (see note in table 2). The HC show the influence in the long-term and the HP in the short-term. In the $\mathrm{HC}$ case, $\mathrm{Xu}$ obtains the first position with 44 papers; the second position is Tong with 41 papers, followed by Shi, Li and Herrera. In the HP case, Li and Tong share the first position with 5 papers, followed by Shi and Wang. Herrera with 185 papers, 16913 citations, h-index of $67,23 \mathrm{HC}$ papers, presented the highest performance at light of the all indicators measures. 
Table 5. List the most influential and productive authors

\begin{tabular}{|c|c|c|c|c|c|c|c|c|}
\hline Author & TPF & $\% \mathrm{PF}$ & TCF & $\begin{array}{l}\text { Average C. } \\
\text { per ítem }\end{array}$ & $\begin{array}{l}\text { Average C } \\
\text {.per year }\end{array}$ & H-index & $\mathrm{HC}$ & HP \\
\hline Pedrycz W & 544 & 0.62 & 11606 & 21.33 & 322.39 & 52 & 7 & 0 \\
\hline Huang Gh & 316 & 0.36 & 5909 & 18.70 & 246.21 & 39 & 1 & 0 \\
\hline Yager RR & 275 & 0.31 & 10520 & 38.25 & 269.74 & 48 & 4 & 0 \\
\hline Wang J & 266 & 0.30 & 3982 & 14.97 & 165.92 & 34 & 8 & 1 \\
\hline Xu ZS & 240 & 0.27 & 10448 & 43.53 & 696.53 & 52 & 44 & 0 \\
\hline Zhang Y & 232 & 0.26 & 1673 & 7.21 & 61.96 & 21 & 4 & 0 \\
\hline Liu Y & 212 & 0.24 & 1587 & 7.49 & 88.17 & 21 & 0 & 0 \\
\hline Li Ym & 209 & 0.24 & 5631 & 26.94 & 312.83 & 36 & 27 & 5 \\
\hline Tong SC & 203 & 0.23 & 8561 & 42.17 & 407.67 & 52 & 41 & 5 \\
\hline Chen SM & 188 & 0.21 & 6420 & 34.15 & 267.50 & 43 & 2 & 0 \\
\hline Herrera F & 185 & 0.21 & 16913 & 91.42 & 768.77 & 67 & 23 & 0 \\
\hline Li HX & 184 & 0.21 & 3526 & 19.16 & 110.19 & 33 & 1 & 0 \\
\hline Liu J & 179 & 0.20 & 2276 & 12.72 & 91.04 & 25 & 0 & 0 \\
\hline Wang Y & 174 & 0.20 & 1307 & 7.51 & 72.61 & 18 & 0 & 0 \\
\hline $\mathrm{Li} \mathrm{Y}$ & 170 & 0.19 & 1785 & 10.50 & 85.00 & 21 & 4 & 0 \\
\hline Shi P & 170 & 0.19 & 7568 & 44.52 & 540.57 & 47 & 40 & 4 \\
\hline Davvaz B & 166 & 0.19 & 2147 & 12.93 & 126.29 & 26 & 2 & 0 \\
\hline Wang L & 163 & 0.18 & 1998 & 12.26 & 83.25 & 22 & 3 & 0 \\
\hline Li J & 156 & 0.18 & 1674 & 10.73 & 88.11 & 22 & 3 & 0 \\
\hline Kahraman C & 150 & 0.17 & 4754 & 31.69 & 297.12 & 41 & 5 & 0 \\
\hline
\end{tabular}

Table 6. Most influential and productive institutions

\begin{tabular}{|c|c|c|c|c|c|c|c|c|}
\hline \multirow[b]{2}{*}{ Institution } & \multirow[b]{2}{*}{ TPF } & \multirow[b]{2}{*}{$\% \mathbf{P F}$} & \multirow[b]{2}{*}{ TCF } & \multirow{2}{*}{$\begin{array}{l}\text { Average } \\
\text { C. per } \\
\text { ítem }\end{array}$} & \multicolumn{2}{|l|}{ Average } & \multirow[b]{2}{*}{ HC } & \multirow[b]{2}{*}{ HP } \\
\hline & & & & & $\begin{array}{l}\text { C .per } \\
\text { year }\end{array}$ & H-index & & \\
\hline Islamic Azad Univ & 1761 & 1.99 & 13874 & 7.88 & 991.00 & 45 & 21 & 0 \\
\hline Indian Inst Technol & 957 & 1.08 & 19106 & 19.96 & 454.90 & 62 & 7 & 0 \\
\hline Univ Tehran & 871 & 0.99 & 8594 & 9.87 & 477.44 & 39 & 9 & 0 \\
\hline Univ Granada & 772 & 0.87 & 28695 & 37.17 & 819.86 & 83 & 41 & 0 \\
\hline Chinese Acad Sci & 725 & 0.82 & 11016 & 15.19 & 393.43 & 49 & 10 & 0 \\
\hline Natl Cheng Kung Univ & 713 & 0.81 & 13164 & 18.46 & 526.56 & 54 & 1 & 0 \\
\hline Hong Kong Polytech Univ & 665 & 0.75 & 13573 & 20.41 & 616.95 & 53 & 9 & 0 \\
\hline Harbin Inst Technol & 659 & 0.75 & 13629 & 20.68 & 425.91 & 60 & 48 & 4 \\
\hline Northeastern Univ & 634 & 0.72 & 9157 & 14.44 & 339.15 & 48 & 15 & 0 \\
\hline Natl Chiao Tung Univ & 619 & 0.70 & 17549 & 28.35 & 531.79 & 64 & 7 & 0 \\
\hline Nanyang Technol Univ & 570 & 0.64 & 11856 & 20.80 & 564.57 & 54 & 7 & 0 \\
\hline Univ Alberta & 569 & 0.64 & 9610 & 16.89 & 291.21 & 49 & 9 & 0 \\
\hline Shanghai Jiao Tong Univ & 560 & 0.63 & 7960 & 14.21 & 331.67 & 45 & 13 & 0 \\
\hline Polish Acad Sci & 555 & 0.63 & 10986 & 19.79 & 267.95 & 50 & 7 & 0 \\
\hline City Univ Hong Kong & 554 & 0.63 & 18089 & 32.65 & 822.23 & 70 & 12 & 0 \\
\hline Natl Taiwan Univ Sci Technol & 543 & 0.61 & 9710 & 17.88 & 539.44 & 52 & 2 & 1 \\
\hline
\end{tabular}

Same abbreviations than Table 2. 


\subsection{Most influential institutions in fuzzy research}

Fuzzy research is performed by institutions around the world. There are many universities with a strong approach on fuzzy research. Focusing on the most influential and productive institutions, with the highest number of fuzzy articles, Islamic Azad University lead the rank with 1761 articles. Table 6 presents a list with of the most influential institutions in fuzzy research according to the number of papers of all time, by overcoming the 500 papers threshold. Others criteria are considered and added in the table to give a complete overview of the influential institutions in the fuzzy science. At the first position according to the h-index and the number of citations, the University of Granada lead the rank with 83 and 28695 respectively, followed by City Univ Hong Konm, Natl Chiao Tung Univ, Indian Inst Technol and Harbin Inst Technol. In the $\mathrm{HC}$ case, Harbin Inst Technol obtains the first position with 48 papers; the second position is Univ Granada with 41 papers, followed by Islamic Azad Univ. In the HP case, Harbin Inst Technol lead with 4 papers, followed by Natl Taiwan Univ Sci Technol.

At the top of the list, the University of California, Berkely is leader in both, citations and number of documents, tripling the next on the list in number of citations, thanks to Zadeh. The second position is occupied by the Tokyo Institute of Technology.

The public institution or agency that is in first position is the National Natural Science Foundation of China, exceeding five times the number of articles as its predecessor.

\subsection{Analysis by highly cited threshold}

Analyzing the hundred most cited articles to all time, and as can be seen in Figure 3 (T100), that draw all period analized, it can identify three groups: those that exceed 10,000 citations, those that are at the halfway point between 1000 and 10,000 citations and those at a basic level which have less than 1000 citations. The most cited document is the oldest paper, than is the base or pioneering document for studies in the field and corresponds to the work of Zadeh (1965). The following most cited document appears over twenty years later and corresponds to the paper of Takagi and Sugeno and the third in number of citations appears ten years later and belongs to Decher, that is, 1985 and 1997, respectively. The decade 1995-2005, concentrates the largest number of documents most cited in fuzzy of all time. It is evident there is a large number of publications in various fields. Moreover, to analyze the most recent period, the documents defined by WoS as "Highly cited papers -HC" have been selected, in order to allow an overview of the trend of citations over the last 10 years. The reasons for selecting this measure is because it permits identify and refine the most influential research papers of the last ten years.
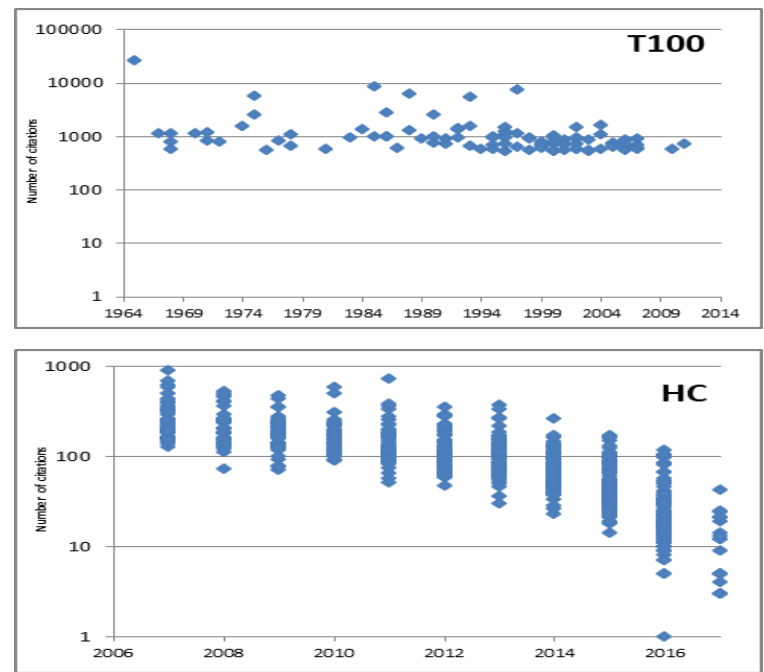

Fig. 3. Top 100 most cited papers and highly cited papers by number of citations by age.

T100, number of the papers in the top 100 most cited papers in fuzzy research of all time. Highly Cited Papers: Selected from the most recent 10 years of data. HC Fuzzy papers: 846 papers. HCP reflect the top $1 \%$ of papers by field and publication year based on a highly cited threshold.

As observed in figure $3(\mathrm{HC})$, the citations follow a trajectory of logarithmic growth in the first four years, with high level of dispersion. At this point it stabilizes over another period of four years, showing less dispersion in the data set.

For the next two years the number of citations increases, but with a much lower rate than beginning of the publication. In the second year the threshold is 10 citations and the seventh year the threshold is 100 citations. None of the documents appoint citations above 1000 at the first ten years of life of publication. This measure can be considered an early impact indicator.

\section{Evolution in the past ten years of fuzzy research areas and regional comparisons}

Changes in the position of the different research areas of fuzzy logic have been analyzed for the period 2007-2016 as shown in Table 7. The first three 
positions by number of articles are in the field of computer science, engineering and mathematics respectively.

The compound annual growth rate (CAGR) 20072016 the largest growth was present in the thermodynamics, followed by science technology other topics, energy fuels, mechanics, Telecommunications and water resources. Physics was the research area that most descended.

It has been established three groups, based on a performance growth factor. The first group corresponds to research area that have gained in position, that we have called "emerging" group, formed by science technology other topics, energy fuels, mechanics, thermodynamics, business economics, environmental sciences ecology and telecommunications. The second group makes up the areas that have not changed their position and in this group are the "pioneers", such as, computing, engineering, mathematics, automation control systems and agriculture. A third group is made up of areas that have lost positions -a "loser group"-, formed by physics, chemistry, instruments instrumentation, geology, operations research management science, water resources, materials science and transportation.

Table 7. Changes in the last ten years by research area

\begin{tabular}{|c|c|c|c|c|c|}
\hline $\begin{array}{l}\text { Rank } \\
2016\end{array}$ & Research Areas & $\begin{array}{l}\text { Papers } \\
2016\end{array}$ & $\begin{array}{l}\text { Variation } \\
07-16 \\
(\%) \\
\end{array}$ & $\begin{array}{l}\text { CAGR } \\
07-16\end{array}$ & $\begin{array}{l}\text { CP } \\
07-16\end{array}$ \\
\hline 1 & Computer Science & 3293 & 124.62 & 9.41 & 0 \\
\hline 2 & Engineering & 2805 & 151.34 & 10.78 & 0 \\
\hline 3 & $\begin{array}{l}\text { Mathematics } \\
\text { Automation Control }\end{array}$ & 983 & 115.10 & 8.88 & 0 \\
\hline 4 & $\begin{array}{l}\text { Systems } \\
\text { Science } \quad \text { Technology }\end{array}$ & 574 & 81.07 & 6.82 & 0 \\
\hline 5 & Other Topics & 452 & 822.45 & 28.00 & 10 \\
\hline 6 & $\begin{array}{l}\text { Business Economics } \\
\text { Environmental Sciences }\end{array}$ & 438 & 287.61 & 16.25 & 2 \\
\hline 7 & $\begin{array}{l}\text { Ecology } \\
\text { Operations } \quad \text { Research }\end{array}$ & 429 & 304.72 & 16.80 & 2 \\
\hline 8 & Management Science & 394 & 62.81 & 5.57 & -3 \\
\hline 9 & Energy Fuels & 346 & 743.90 & 26.74 & 9 \\
\hline 10 & $\begin{array}{l}\text { Instruments Instrumen- } \\
\text { tation }\end{array}$ & 247 & 105.83 & 8.35 & -4 \\
\hline 11 & Water Resources & 232 & 217.81 & 13.71 & -1 \\
\hline 12 & Telecommunications & 183 & 266.00 & 15.51 & 2 \\
\hline 13 & Mechanics & 178 & 323.81 & 17.40 & 4 \\
\hline 14 & Physics & 178 & 56.14 & 5.08 & -7 \\
\hline 15 & Geology & 172 & 177.42 & 12.01 & -4 \\
\hline 16 & Materials Science & 143 & 155.36 & 10.98 & -3 \\
\hline 17 & Chemistry & 136 & 126.67 & 9.52 & -5 \\
\hline 18 & Thermodynamics & 114 & 1040.00 & 31.05 & 30 \\
\hline 19 & Transportation & 111 & 152.27 & 10.83 & -3 \\
\hline 20 & Agriculture & 86 & 145.71 & 10.50 & 0 \\
\hline
\end{tabular}

\subsection{Regional Comparisons}

In each country and region disparities in the level of the economic developed are very large and persistent. Factors of localization or concentration of knowledge, could inform of keys patterns of growth and technological progress. In this section, the last ten years of the period have been analyzed, that is from 2007 to 2016. Fuzzy scientific production is very volatile as it can see when calculating annual growth rates. However, for the period analysed (2007-2016), the compound annual growth rate has been calculated and can be seen that on average scientific production grew at an annual rate of 12.78 percent. López-Herrera et al. [27] have studied some specific aspects about bibliometric mapping. They analyzed the evolution in fuzzy sets research for the Spanish region.

Figure 4 shows the compound annual growth rates of scientific production in fuzzy logic for 2007-2016 by regional aggregate where it is found that three regions (or country groupings) are below the global average and eight are above this. The lower performance is seen in the G7-group of developed countries- and North America who have a very similar growth below 7 percent. The highest growth is in the Middle East and North Africa, with 24.43 percent, followed by Sub-Saharan Africa with 22.43 percent, South Asia with 20.84 percent.

The notable increase in fuzzy research in the Middle East and North Africa is highly represented by research in Iran, Saudi Arabia and Algeria. Analyzing these cases, we did not find authors or influential journals. There is a great concentration in the case of analysis by institutions. In the case of Iran, there is a significant increase in the number of publications for the Islamic Azad University (IAU). This increase has been presented mainly in the application of fuzzy logic in fields of engineering, computer science artificial intelligence and mathematics. Last but not least, a large number of documents were found that involved the recent concept of hesitant fuzzy setsHFS and its extensions. The increase that has been presented in IAU can be highly linked with the creation and development of research centers in that institution and its strategy of consolidation as a global center of high performance.

Large participation can be seen in the developing countries, and decrease in developed countries is evident. How it is known, the research has long been an important driver of technological progress. 


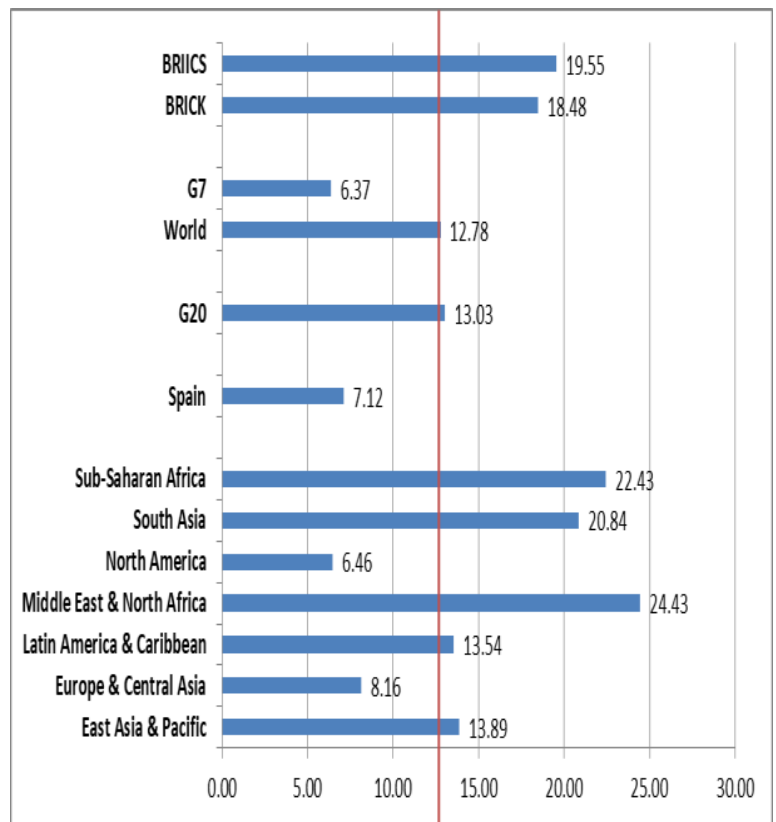

Fig. 4. Compound Annual Growth Rate 2007-2016 fuzzy research by regional aggregation.

Note: BRIICS: Brazil, Russia, Indonesia; India; China and South Africa. BRICK: Brazil, Russia, India, China and South Korea. G7: Germany, Canada, United States, France, Italy, Japan and United Kingdom.

Source: Own elaboration from WoS

\section{Conclusions}

This study has been presented a bibliometric analysis of fuzzy research, giving a general overview of the leading trends that have occurred in the fuzzy research between 1970 and 2017. Research has allowed us to measure scientific production of fuzzy logic and performance on multiple levels, offering an integral overview of the field by researchers, journals, countries, regions and institutions, with the use/application of different bibliometric metrics.

In half a century of fuzzy logic research, it is evident that there exists a path of progress and achievements in the field. Research has developed and facilitated the implementation of tools for various fields of science, contributing to the trans-disciplinary field. The number of contributions has exceeded 173,695 records in five decades, the global h-index is at 295, the boom of documents occurred in the 1995-2005 period. The largest number of documents was in 2016, exceeding 14,300 records, the most cited document exceeds 26,228 citations, the number of highly cited paper is 846 and the hot papers are 26. In the early years, applications were mainly in the engineer- ing fields and logical developments. Subsequently, it advanced to applied systems, and in the 80 s to the application of information technology and its foray into the development of the image which gave importance to areas of health, mainly in scanning, physics and optics. This foray into the social sciences made an early appearance in the 70s (Business, Management) with a work on decision-making. However, its growth is in the 90s. An early appearance is also recorded in 1975, with an experimental work on control systems applications in linguistics (computer science and psychology). Applications developed in the field of management appear first in business and then in operations. The ability of fuzzy logic to play a role in the integration of disciplines is evident. As well as this, fuzzy logic plays a role in the support of disciplinary boundaries with a high commitment to society.

Most developed articles have been in computer science, information technology, engineering, automation, mathematics and physics.

The most influential author in the field is Zadeh. He has contributed immensely to the field. What he has brought to the field is surprising since his work is pioneer in many fields and applications. He is the first in the area of information technology by numbers of citation. His works have increased the rankings of the institutions which he is a member of as well as the profile of the journals which have disseminated his research.

The most influential journal is Fuzzy Sets and Systems. Most contributions are from the United States. However, scientific production in the field for countries that were considered leaders has declined ushering in emerging countries. A rapid growth is seen in China, India, Saudi Arabia, South Africa, Indonesia, Mexico, Australia and Brazil and a noticeable decrease in Japan. The United States, Germany and the United Kingdom continue to grow at levels well below average. The global nature of the field is evidenced by a large number of researchers from different countries and continents. Collaborative networks have enabled the development of applications around the world, leading to increased production in the field.

It was found that the average number of pages per article is twenty. The average number of references cited per document is sixty. The average annual number of citations is forty-five.

The methodology used enriched the exercise and allowed a consistent analysis with limited data.

Advances are emerging within the scientific community in the field. The Government in China 
provides financial support for R\&D which is reflected in the growth of scientific production. The support by the state and institutions increases production levels and helps the development of knowledge in the regions and economic progress.

The trends point to specific areas of science and technology sectors such as thermodynamics, science technology, energy fuel, geology, mechanics, business economics and environmental sciences ecology.

New developments in the use of new materials, clean and sustainable energy developments, technologies applied to the development of industry such as biotechnology, and application to management fields; constitute a potential scenario that will undoubtedly mark the future trajectory of the areas where fuzzy theories will be present. It is as answer to the needs of applications. However, it is expected that the publications and citations will continue to grow. Moreover, open access and social networks will promote involving researchers, institutions, governments and politicians all over the world.

The study has provided support for the decisionmaking in institutions, governments as well; it is a complementary tool to comprehensive evaluation of research and researchers. It is a general orientation of the most influential research.

Making reference to the limitations, we mention that we know the limitations that the indicators used present. Likewise, the database used does not include the total production of the field, neither it include the all editorial material or ways of diffusion of the all science. Similarly, the use/download of documents is not available. Comprehensive evaluation involves taking into account a whole series of elements that are not currently available, neither are metrics available for doing so. Current metrics are impact-based. The "qualities" or qualitative elements such as experience, specialization and training are not measured as a factor of evaluation, which is a challenge to develop future work. The development of metrics or methodologies that allow a greater coverage and quantification of the measurement is suggested; involving people and institutions, and their profiles.

Current trends lead to the evaluation of texts online, developing more accurate and sophisticated immediacy metrics and indicators. The last decade has seen a growing interest in bibliometric methods, motivated by the use of visualization tools that collect information for decision-making.

Future work should focus on the improved or development of new metrics for the evaluation of science, in the era of open and immediate services. Next generation indicators should contain standardized, ro- bust, open and global data, including measurements on social media platforms, and with the active participation of all stakeholders.

\section{References}

[1] S. Alonso, F.J. Cabrerizo, E. Herrera-Viedma and F. Herrera, H-index: a review focused on its variants, computation and standarization for diferent scientific fields, Journal of Informetrics 3 (2009), 273-289.

[2] B.H. Baltagi, Worldwide econometrics rankings: 1989-2005, Econometric Theory 23 (2007), 952-1012.

[3] F. Blanco-Mesa, J.M. Merigó and A.M. Gil-Lafuente, Fuzzy decision making: A bibliometric-based review, Journal of Intelligent \& Fuzzy Systems 32 (2017), 2033-2050

[4] S.C. Bradford, Sources of information on specific subjects, Engineering 137 (1934), 85-86.

[5] H. Bustince, F. Herrera and J. Montero, Fuzzy Sets and Their Extensions: Representation, Aggregation and Models, Intelligent Systems from Decision Making to Data Mining, Springer, Berlin, Germany, 2008.

[6] C. Cansino, J.M. Merigó, F. Coronado, Y. Dessouky and M. Dessouky, Forty years of Computers \& Industrial Engineering: A bibliometric analysis, Computers \& Industrial Engineering 113 (2017), 614-629.

[7] S.G. Carrizo, La información en ciencias sociales, Trea, Madrid, Spain, 2000.

[8] M.J. Cobo, A.G. López-Herrera, E. Herrera-Viedma, and F. Herrera, An approach for detecting, quantifying, and visualizing the evolution of a research field: A practical application to the Fuzzy Sets Theory fiel, Journal of Informetrics 5 (2011), 146-166.

[9] F.J. Cole and N.B. Eales, The history of comparative anato$m y$, Science Progress, London, 1917.

[10] D. Dubois and H. Prade, Fuzzy sets and systems: Theory and aplications, Academic Press, New York, 1980.

[11] A. Emrouznejad and A. Mara, Ordered weighted averaging operators 1988-2014. A citation based literature survey, International Journal of Intelligent Systems 29 (2014), 9941014

[12] J. Fagerberg, M. Fosaas and K. Saprasert, Innovation: exploring the knowledge base, Research Policy 41 (2012), 1132-1153.

[13] E. Garfield, Citation Indexes for Science, Science 122 (1955), 108-111.

[14] E. Garfield, Citation analysis as a tool in journal evaluation, Science 178 (1972), 471-479.

[15] M. Gaviria-Marin, J.M. Merigó and S. Popa, Twenty years of the Journal of Knowledge Management: abibliometric analysis, Journal of Knowledge Management 22 (2018), 16551687.

[16] B. González-Pererira, V. Guerrero-Bote and F. MoyaAnegón, A new approach to the metric of journals' scientific prestige: The SJR indicator, Journal of Informetrics 4 (2010), 379-391.

[17] P.L.K Gross and E.M. Gross, College libraries and chemical education, Science 66 (1927), 385-389.

[18] D.T. Hawkins, Unconventional Uses of Online Information Retrieval Systems: Online Bibliometric Studies, Journal of the American Society for Information Science 28 (1977), 1318. 
[19] J.E Hirsch, An index to quantify an individual's scientific research output, PNAS 102 (2005), 16569-16572. http://www.pnas.org/content/102/46/16569

[20] G.F.A. Hoepner, B. Kant, B. Scholtens and P.S. Yu, Environmental and ecological economics in the 21st century: an age adjusted citation analysis of the influential articles, journals, authors and institutions, Ecological Economics 77 (2012), 193-206

[21] W. Holsapple and A. Lee-Post, Behavior-based analysis of knowledge dissemination channels in operations management, Omega 38 (2010), 167-178.

[22] P.N. Hsieh and P.L. Chang, An assessment of world-wide research productivity in production and operations management, International Journal of Production Economics 120 (2009), 540-551.

[23] E.W. Hulme, Statistical Bibliography in Relation to the Growth of Modern Civilization, Graton, London, UK, 1923.

[24] Z.G. Kingsley, The Psycho-Biology of Language: An Introduction to dynamic Philology, Riverside Press, Cambridge, UK, 1935.

[25] G.J.Klir and B. Yuan, Fuzzy sets and fuzzy logic: Theory and Applications, Prentice Hall PTR, New York, 1995.

[26] W. Liu and H. Liao, A bibliometric analysis of fuzzy decision research during 1970-2015, International Journal of Fuzzy Systems 19 (2017), 1-14.

[27] A.G. López-Herrera, M.J. Cobo, E. Herrera-Viedma and F. Herrera, Visualization and evolution of the scientific structure of fuzzy sets research in Spain, Information research 14 (2009), 1-23.

[28] A.J. Lotka, The frequency distribution of scientific productivity, Journal Washington Academy Science 16 (1926), 317 323.

[29] M.A. Martínez, M. Herrera, J. López-Gijón and E. HerreraViedma, H-Classics: characterizing the concept of citation classics through H-index, Scientometrics 98 (2014), 19711983.

[30] J.M. Merigo, A.M. Gil-Lafuente and R.R. Yager, An overview of fuzzy research with bibliometric indicators, Applied Soft Computing 27 (2015), 420-433.

[31] J.M. Merigó, A. Rocafort and J.P. Aznar-Alarcón, Bibliometric Overview of Business \& Economics Research, Journal of Business Economics and Management 17 (2016), $397-$ 413.

[32] J.M. Merigó, F. Blanco-Mesa, A.M. Gil-Lafuente and R.R Yager, Thirty years of the International Journal of Intelligent Systems: A bibliometric review, International Journal of Intelligent Systems 32 (2017), 526-554.

[33] J.M. Merigó, W. Pedrycz, R. Weber and C. dela Sotta, Fifty years of Information Sciences: A bibliometric overview,Information Sciences 432 (2018), 245-268.

[34] P. Otlet, Tratado de Documentación, Traducción de María Dolores Ayuso, Universidad De Murcia, Murcia, Spain, 2008.

[35] A. Pilkington and J. Meredith, The evolution of the intellectual structure of operations management 1980-2006: a citation/cocitation analysis, Journal of Operations Management 27 (2009), 185-202.

[36] P.M. Podsakoff, S.B. Mackenzie, N.P. Podsakoff and D.G. Bachrach, Scholarly influence in the field of management: a bibliometric analysis of the determinants of university and author impact in the management literature in the past quarter century, Journal of Management 34 (2008), 641-720.

[37] A. Pritchard, Statistical bibliography: An interim bibliography, Journal of Documentation 25 (1969), 348-349.

[38] L.M. Raising, Statistical bibliography in the health sciences, Bulletin of the Medical Library Association 50 (1962), 450461 .
[39] Thomson Reuters. Web of Science-WoS. Core collection database.

[40] I.B. Turksen and D.D.W. Yao, Representation of connectives in fuzzy reasoning: The view through normal forms, IEEE Trans. on Systems, Man and Cybernetics 14 (1984), 146-151.

[41] I.B. Türksen, Interval valued fuzzy sets based on normal forms, Fuzzy Sets and Systems 20 (1986), 191-210.

[42] N.J. Van Eck and L. Waltman, Bibliometric mapping of the computational intelligence field, International Journal of Uncertainty Fuzziness and Knowledge-Based Systems 15 (2007), 625-645

[43] L. Waltman and N.J. Van Eck, A smart local moving algorithm for large-scale modularity-based community detection, The European Physical Journal B, 86 (2013), 471.

[44] W. Wang, S. Laengle, J.M. Merigó, D. Yu, E. HerreraViedma, M.J. Cobo and B. Bouchon-Meunier, A Bibliometric Analysis of the First Twenty-Five Years of the International Journal of Uncertainty, Fuzziness and KnowledgeBased Systems, International Journal of Uncertainty, Fuzziness and Knowledge-Based Systems 26 (2018), 169-193.

[45] H.D. White and K. McCain, Bibliometrics, Annual review of information science and technology 24 (1989), 119-186.

[46] R.R. Yager, On ordered weighted averaging aggregation operators in multi-criteria decision making", IEEE Transactions on Systems, Man and Cybernetics 18 (1988), 183-190.

[47] D. Yu, A scientometrics review on aggregation operator research, Scientometrrics 105 (2015), 115-133.

[48] D. Yu and S.S. Shi, Researching the development of Atanassov intuitionistic fuzzy set: Using a citation network analysis, Applied Soft Computing 32 (2015), 189-198.

[49] D. Yu, D.F. Li, J.M. Merigó and L. Fang, Mapping development of linguistic decision making studies, Journal of Intelligent \& Fuzzy Systems 30 (2016), 2727-2736.

[50] L.A. Zadeh, "Fuzzy sets", Information and Control 8 (1965), 338-353.

[51] L.A. Zadeh, Fuzzy sets as a basis for a theory of possibility, Fuzzy Sets and System 1 (1978), 3-28.

[52] L.A. Zadeh, Is there a need for fuzzy logic?, Information Sciences 178 (2008), 2751-2779.

[53] H. Zijlstra and R. McCullough, CiteScore: a new metric to help you track journal performance and make decisions, Elsevier Editors' update, 2016. access online: https://www.elsevier.com/connect/editors-update

[54] H.J. Zimmermann, Fuzzy Set Theory and its Applications, Klumer Academic Publishers, Boston, 1985.

[55] B. Zogala-Siudem, G. Siudem, A. Cena and M. Gagolewski, Agent-based model for the h-index - exact solution, The European Physical Journal B 89 (2016), 1-9. 